\title{
Knowledge, Attitude and Practice on Mouth Mirrors Used for Endodontic Procedures Among Dental Students-A Questionnaire Survey
}

\author{
Ranjith Raj ${ }^{1}$ and Raghu Sandhya ${ }^{2}$ \\ ${ }^{1}$ Saveetha Dental College, Saveetha Institute of Medical and \\ Technical Sciences, Saveetha University, Chennai - 600077, India \\ ${ }^{2}$ Reader Department of Conservative Dentistry and Endodontics, Saveetha Dental College and \\ Hospitals, Saveetha Institute of Medical and Technical Sciences, Saveetha University, 600077, India
}

\section{ABSTRACT}

Oral hygiene and health is vital and important for an individual for better quality of life.There are various methods to treat dental caries however proper diagnosis is required for any disease on treatment. Mouth mirror being a vital tool for proper diagnosis, the proper knowledge, awareness and the usage of it is essentially required. This study aims to assess the knowledge, attitude and practice on mouth mirrors used for endodontic procedures among dental students. A questionnaire based study was conducted online using a survey planet link. 100 participants took part in the survey who were undergraduate or postgraduate dental students. A total of 30 questions were asked and the questions were based on their knowledge, attitude and practice of mouth mirrors used in endodontic procedures. Based on the responses from the participants, results were analysed and tabulated systematically. Data was analysed by descriptive statistics and chi-square tests using SPSS. 51\% of participants stated that they were aware of the parts of a dental mirror. 61\% of the participants stated that it was difficult to do endodontic procedures using mouth mirrors. $60 \%$ of the participants were aware that the front surface is the best mirror for avoiding double images. 53\% of the participants found it difficult to clear fog and debris from mouth mirrors during endodontic treatment.76\% of the participants found the survey to be useful.This study produced satisfactory results yet more awareness on the proper selection and usage of the dental mirror is required

KEY WORDS: ARMAMENTARIUM, ENDODONTICS, FIELD OF VIEW, INDIRECT VISION, MOUTH MIRRORS.

\section{INTRODUCTION}

Oral hygiene and health is vital and important for an individual for better quality of life. Disease and health problems are rapidly increasing in India mainly in the

\section{ARTICLE INFORMATION}

${ }^{*}$ Corresponding Author: sandhya.sdc@saveetha.com Received 28th July 2020 Accepted after revision 25th Sep 2020 Print ISSN: 0974-6455 Online ISSN: 2321-4007 CODEN: BBRCBA

Thomson Reuters ISI Web of Science Clarivate Analytics USA and Crossref Indexed Journal

\section{Clarivate
Analytics}

NAAS Journal Score 2020 (4.31) SJIF: 2020 (7.728)

A Society of Science and Nature Publication,

Bhopal India 2020. All rights reserved.

Online Contents Available at: http//www.bbrc.in/

Doi: http://dx.doi.org/10.21786/bbrc/13.8/154 oral and dental health. Tooth decay also known as dental caries is a multifactorial disease which is most common in Indian population.(Selwitz, Ismail and Pitts, 2007; Anwar, 2018) Each and every person is susceptible to tooth decay or dental caries throughout their lifetime.(Ozdemir, 2014) Maintaining oral health is mainly done by the individual and partly by the dentist but both play a vital role in maintaining better hygiene. Frequent visit to a dentist is one of the main responsibilities of an individual and proper diagnosis and treatment are the fundamental goals of a dentist. There are various methods to treat dental caries however proper diagnosis is required for any disease on treatment. 
Proper armamentarium plays a major role in diagnosis, one such armamentarium is the mouth mirror otherwise known as dental mirror which is the most basic and vital armamentarium for proper diagnosis. It is a handy tool, small in size, consisting of a metal bar as a handle and a metal plate for holding the mirror.(Rubinstein, 1997) The use and the functions of a mouth mirror is versatile. It is used for illumination, indirect vision, retractions of soft tissues such as the tongue, lips, buccal mucosa of the cheek, used for checking mobility, percussion of teeth and functions as such.(Rieuwpassa et al., 2016) The mouth mirrors are also available in various sizes and types according to the usage and function. Mouth mirror being a vital tool for proper diagnosis, the proper knowledge, awareness and the usage of it is essentially required.

We have numerous highly cited publications on well designed clinical trials and lab studies (Govindaraju, Neelakantan and Gutmann, 2017; Azeem and Sureshbabu, 2018; Jenarthanan and Subbarao, 2018; Manohar and Sharma, 2018; Nandakumar and Nasim, 2018; Teja, Ramesh and Priya, 2018; Janani and Sandhya, 2019; Khandelwal and Palanivelu, 2019; Malli Sureshbabu et al., 2019; Poorni, Srinivasan and Nivedhitha, 2019; Rajakeerthi and Ms, 2019; Rajendran et al., 2019; Ramarao and Sathyanarayanan, 2019; Siddique and Nivedhitha, 2019; Siddique et al., 2019; Siddique, Nivedhitha and Jacob, 2019). This has provided the right platforms for us to pursue the current study. This study aims to assess the knowledge, attitude and practise on mouth mirrors used for endodontic procedures among dental practitioners.

\section{MATERIAL AND METHODS}

A questionnaire based study was conducted online using a survey planet link. The study was approved by the institutional review board. 100 participants who gave consent to furnish the questionnaire took part in the survey. The participants who undertook the survey were undergraduate and postgraduate dental students. A total of 30 questions were asked and the questions were based on their knowledge, attitude and practice of mouth mirrors used in endodontic procedures. Based on the responses from the participants, results were analysed and tabulated systematically. Descriptive statistics and Chi square tests were used to analyse the data.

\begin{tabular}{|c|c|}
\hline QUESTIONS & ANSWER DISTRIBUTION \\
\hline $\begin{array}{l}\text { 1.Are you aware of the parts of a dental mirror? } \\
\text { A.Yes } \\
\text { B. No }\end{array}$ & $\begin{array}{l}49 \% \\
51 \% \\
\end{array}$ \\
\hline $\begin{array}{l}\text { 2.Are you aware that there are various types of dental mirror } \\
\text { based on the surface of the mirror used? }\end{array}$ & \\
\hline $\begin{array}{l}\text { A.Yes } \\
\text { B. No }\end{array}$ & $\begin{array}{l}61 \% \\
39 \%\end{array}$ \\
\hline $\begin{array}{l}\text { 3.Are you aware that the dental mirrors are classified based } \\
\text { on the various types of function and usage? }\end{array}$ & \\
\hline $\begin{array}{l}\text { A. Yes } \\
\text { B. No }\end{array}$ & $\begin{array}{l}63 \% \\
37 \%\end{array}$ \\
\hline $\begin{array}{l}\text { 4.Are you aware that the dental mirrors are classified } \\
\text { based on the various sizes available? }\end{array}$ & \\
\hline $\begin{array}{l}\text { A. Yes } \\
\text { B. No }\end{array}$ & $\begin{array}{l}64 \% \\
36 \% \\
\end{array}$ \\
\hline $\begin{array}{l}\text { 5.Are you aware that the self cleansing mirror|mirror with suction } \\
\text { is the best mirror for preventing fog and debris during restorative } \\
\text { procedure? } \\
\text { A. Yes } \\
\text { B. No }\end{array}$ & $\begin{array}{l}76 \% \\
24 \%\end{array}$ \\
\hline $\begin{array}{l}\text { 6.Are you aware that mirrors with magnification help in } \\
\text { better identification of access openings during endodontic treatment? } \\
\text { A. Yes } \\
\text { B. No }\end{array}$ & $\begin{array}{l}79 \% \\
21 \%\end{array}$ \\
\hline
\end{tabular}

\section{RESULTS AND DISCUSSION}

From the results obtained from the questionnaire based survey on the knowledge attitude and practice on mouth mirrors used for endodontic procedures it is found that $40 \%$ of the participants were of the $3 \mathrm{rd}$ year of study, where they were just introduced to the clinical environment followed by $22 \%$ final year students 
followed by interns 14\%. [Figure:1] It is important to realise that introducing a dental mirror at the early stage of the preclinical studies is very essential in coping with the efficiency and usage of the tool for proper situations. (Kunovich, Rosenblum and Beck, 1987) It was found that mouth mirrors were used 3+times a day by $47 \%$ followed by $28 \%$ who used 1-3 times per day. It is evident that the dental mirror is one of the most used tools in dentistry which is very significant in diagnosis. (Díaz et al., 2001) [Table:3]

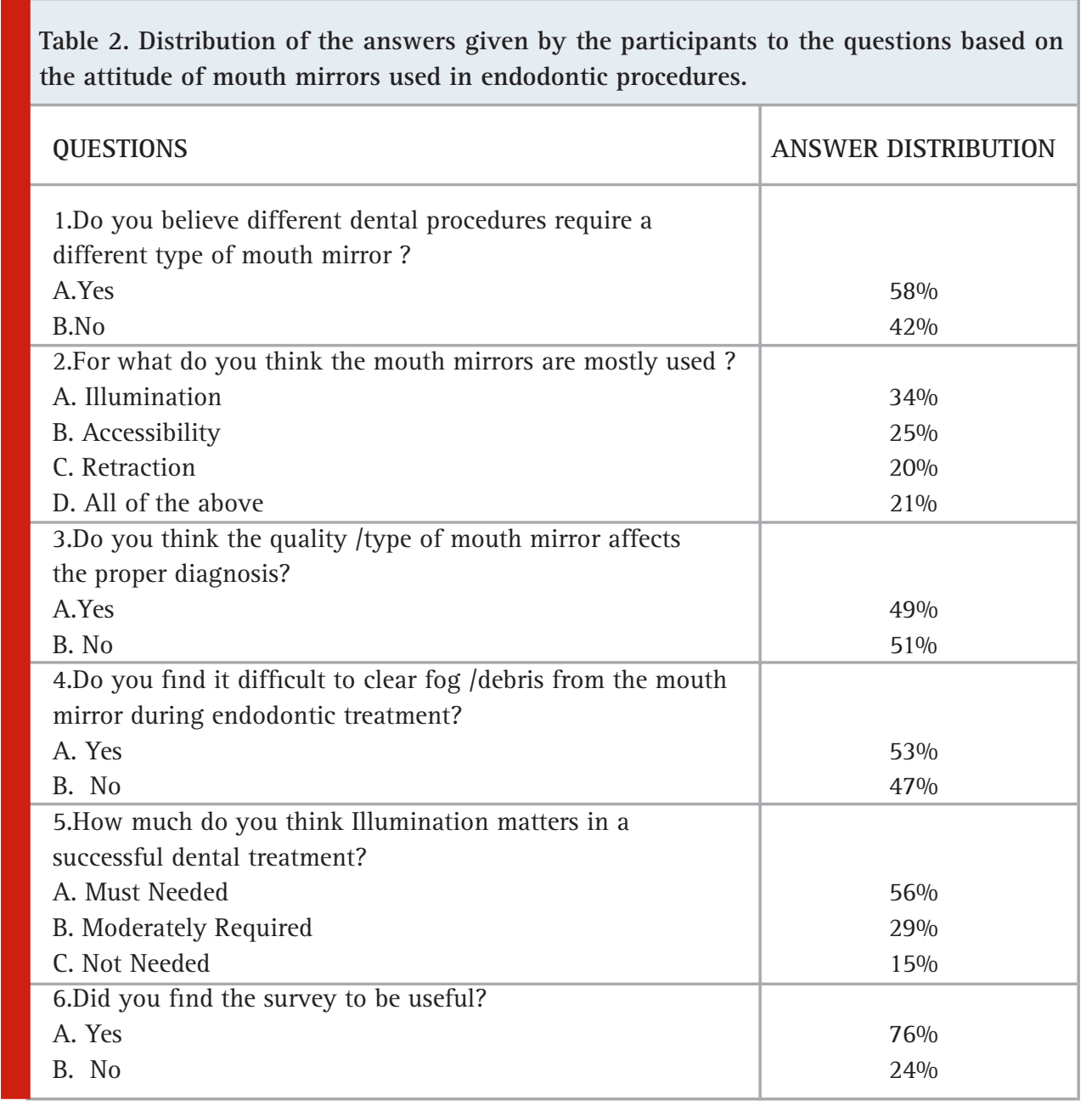

Interestingly $51 \%$ of them answered that they were not aware about the parts of a dental mirror. The parts of the dental mirror are as follows:The head, The Handle. It is to be noted that though a majority used dental instruments, the basic and simple knowledge about its parts were not aware by almost half of the respondents. (Dimashkieh, 2002)[Table:1] There are various purposes of dental mirrors such as illumination, indirect vision, retraction. When asked about the most used function 34\% reported illumination. Illumination is one of the most required characteristics in endodontics followed by $25 \%$ using it to gain access. $20 \%$ use it for retraction and the remaining $21 \%$ of them used it for all of the above functions.(Chalmers et al., 2005)[Table:2] The various types of surfaces which are used in the manufacturing of a dental mirror for various functions are concave surface, front surface, back surface and double sided mirror.(Rubinstein, 2005) 61\% were aware that there were various types of mouth mirrors based on the surface of the mirror . [Table:1]
$28 \%$ of the study population accepted that they prefer backs surface mirror for endodontic procedures however front surface mirror is the most acceptable as it avoids double images which were found to be preferred by only $18 \%$ of the participants.[Table :3] This indicates the lack of knowledge and improper practice of a mirror during a dental procedure.(Kim and Baek, 2004) The various types of dental mirrors concave surface, front surface, back surface and double sided mirror, rhodium coated mirrors, disposable mirrors, mirrors with LED, self cleansing mirror. 63\% were aware that dentals mirrors are classified based on the various types and functions.[Table:1] This illustrates the proper knowledge of the various types of mirrors available among the respondents. Based on the types of mirror which the participants were well aware of are as of the order, it goes by rhodium coated 25.1\%, plastic disposable mirrors $19.3 \%$ self cleansing mirror reference) $18.9 \%$, led mirror 13.2\%, double sided mirror 6.6\%.(Surathu and Nasim, 2015).

Mostly the mirrors had a fixed handle length where the size of the head alone changed subjectively. The available 
sizes are 01, 02, 03, 04, 05, the most common are size $04,05.64 \%$ of the participants were aware that dental mirrors were as of various sizes.[Table:1] When asked about the preference of mirrors size 45\% reported they didn't prefer any specific size and 28\%responded that they do prefer followed by $27 \%$ who might prefer at times.(Knight and Guenzel, 1994)[Table:3].

Table 3. Distribution of the answers given by the participants to the questions based on the practice of mouth mirrors used in endodontic procedures.

\begin{tabular}{l|c}
\hline QUESTIONS & ANSWER \\
DISTRIBUTION
\end{tabular}

1.How often do you use a mouth

mirror ?
A. 1-3 Times a day
$47 \%$
B. 3+Times a day
$28 \%$
C. Nil
$25 \%$

2.Which type of mirror do you prefer for

endodontic procedures?

A. Front surface mirror

$18 \%$

B. Back surface mirror

$28 \%$

C. Concave surface mirror

$32 \%$

D. Plane surface mirror

$22 \%$

3.Do you have any preference in the

size of a dental mirror?

A. Yes

B. No

C. Yes, occasionally

4.Do you use a mouth mirror for indirect

vision while handling maxillary teeth ?

A. Yes, at all times

B. Few times,occasionally

C. No,Not at all

5.How do you manage fog /debris in the

mouth mirror during endodontic

treatment?

A. Wiping the mirror with cotton

B. Using 3 way syringe

$28 \%$

C. By spraying a layer of water over

$32 \%$

the mirror during the treatment

The association of the graduation level and the surface of mouth mirror showed that concave surface mirror is the most preferred mirror among the undergraduates $(30 \%)$ and plane surface is the most preferred among postgraduate students (4\%). The association between the year of study and the preferred mouth mirror surface had no significant difference. $p=.259$ [Figure:6].

$44 \%$ reported that they use mouth mirrors for handling maxillary teeth at all times followed by $39 \%$ occasionally. [Table:3] 58\% of the participants believe different dental procedures require different types of mouth mirror [Figure:4], contradictingly 51\% of the participants didn't agree that dental mirror affects the proper diagnosis. No matter how much a practitioner is well experienced in diagnosing, proper armamentarium is essential, so this is debatable.[Table:2]

There are various hurdles which has to be overcome while using a dental mirrors such as double images, fogging and difficulties as such, $53 \%$ complained that they had difficulty in clearing the fog during treatment[Table:2], To overcome this $40 \%$ reported that they'll use cotton to wipe the fog followed by $32 \%$ who would spray a layer of water over the mirror prior to the treatment.[Table:3] $76 \%$ of the participants were aware that self cleansing mirror with suction is better to avoid fogging.(Willis and Kincheloe, 1983; Neumann, 1988)[Table:1].

Figure 1: Bar graph depicting the frequency distribution of the participants based on the year of study. $\mathrm{X}$ axis represents the year of study and $Y$ axis represents the frequency of the respective year of study in percentage. Majority $40 \%$ of the participants were of the $3 \mathrm{rd}$ year of study where they were just introduced to the clinical environment followed by $22 \%$ final year undegraduate students.

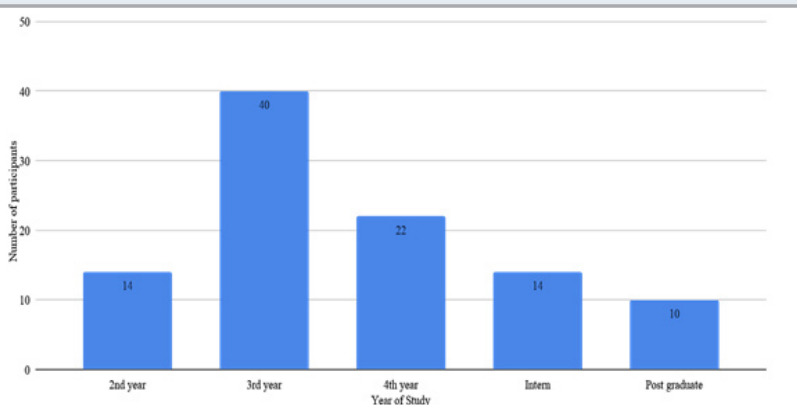

Figure 2: Bar graph representing the responses of the study population regarding the importance of illumination in a dental treatment. $\mathrm{X}$ axis represents the choice of response and $\mathrm{Y}$ axis represents the percentage of response in the corresponding choice. Majority of the participants (56\%) felt that illumination is 'must needed' in a dental treatment followed by (29\%) who felt it is moderately required and $(15 \%)$ who felt it is not much needed.

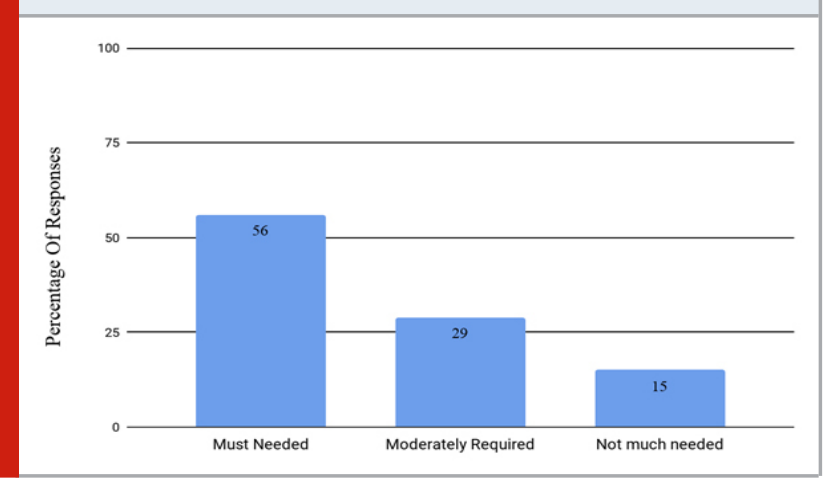

Accessibility, visibility and illumination are few of the main requirements to complete a dental procedure. $61 \%$ were not aware that LED with illumination is best 
for endodontic procedures for better illumination and visibility.[Table:1] 79\% were aware that mirrors with magnification help in identifying the canals.[Table:2] 56 $\%$ answered that illumination is very vital in any dental treatment at all time followed by $29 \%$ of the respondents who answered it is moderately required.[Figure:2](Willis, Scheetz and Kincheloe, 1987; Mital et al., 2014).

When questions were asked about the usage of dental mouth mirrors, 36\% of the participants preferred disposable mouth mirrors for diagnostic purposes. It is evident that sterilisation of dental mirrors only will remove all the organisms. [Figure:4] However when questioned about sterilisation after usage 44\% responded they'll sterilise it by autoclaving after every use followed by $32 \%$ who used only sterillium when required. (Ganavadiya et al., 2014)[Table:3].

Figure 3: Bar graph representing the responses of the study population regarding their belief regarding the usage of different types of mouth mirror for different procedures.X axis represents the choice of response and $\mathrm{Y}$ axis represents the percentage of response in the corresponding choice. Majority of the participants (58\%) felt that different types of mouth mirror is required for different procedures followed by (36\%) who felt it is not needed.

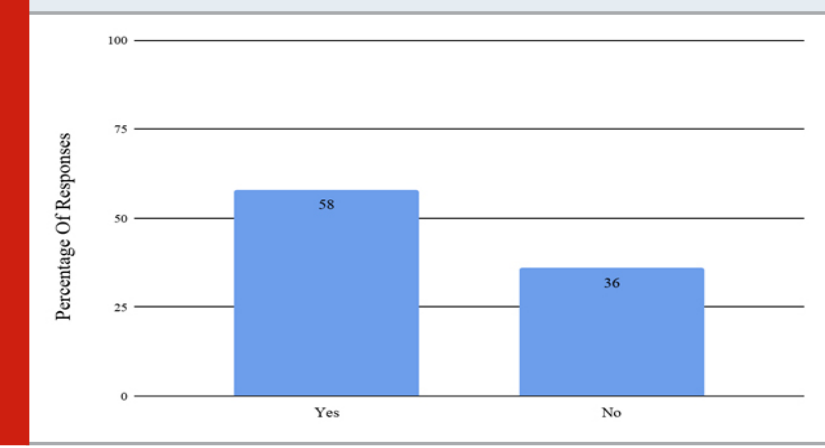

Figure 4: Bar graph representing the responses of the study population regarding their preference of different types of mouth mirrors. $\mathrm{X}$ axis represents the different types of mouth mirrors and $\mathrm{Y}$ axis represents the percentage of response in the corresponding choice. Majority of the participants (36\%) preferred disposable mouth mirror followed by stainless steel mouth mirror (25\%), Mirror with LED (21\%), Back surface mirror (12\%) and the least preferred type of mirror was rhodium coated mirror $(6 \%)$

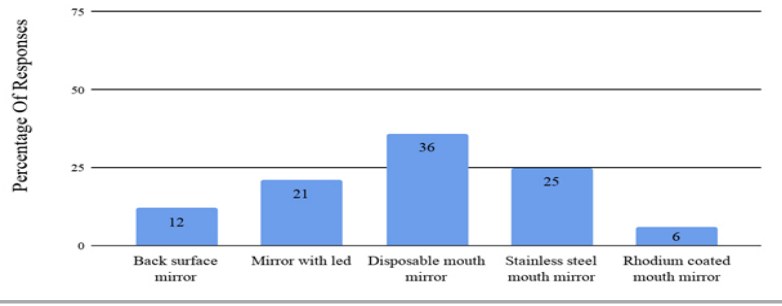

Figure 5: Bar graph representing the responses of the study population regarding their choice to opt for a better mouth mirror after this survey. $\mathrm{X}$ axis represents the choice of response and $\mathrm{Y}$ axis represents the percentage of response in the corresponding choice. Majority of the participants $(65 \%)$ agreed that they will invest in a good quality mouth mirror followed by (35\%) who felt it is not needed.

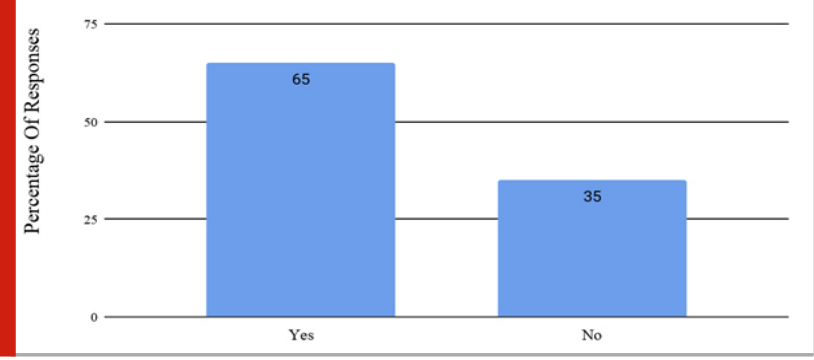

Figure 6: Bar graph depicting the association between the graduation level and the preferred mouth mirror surface. $\mathrm{X}$ axis represents the preferred surface of mouth mirror and $\mathrm{Y}$ axis represents the frequency of responses of the surface of mirror preferred. It is found that concave surface mirror is the most preferred 30\% mirror among the undergraduates(blue) and plane surface is the most preferred $4 \%$ among post graduate students(green). The association between the year of study and the preferred mouth mirror surface was statistically not significant. Chi square test, $\mathrm{p}=.259$ ( $\mathrm{P}>0.05)$.

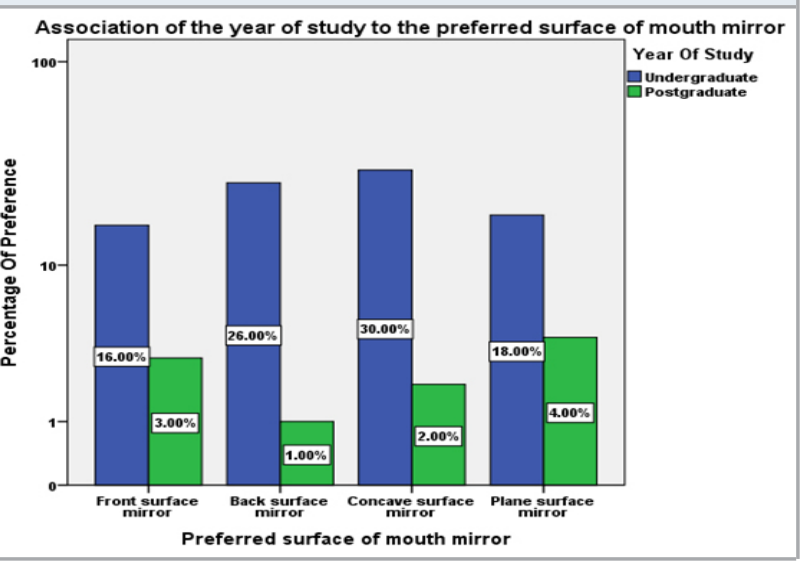

$65 \%$ of the participants accepted to invest in a good quality mouth mirror after completing the survey[Figure:5] and 76\% found the survey to be useful. [Table:2]After analysis of the results obtained from the survey, it did produce quite unsatisfactory results however the participants were interested in updating themselves regarding the knowledge attitude and practice on dental mirrors hence more awareness on the proper selection and usage of the dental mirror.

\section{CONCLUSION}

Dental mirror being an important armamentarium 
available in various forms proper knowledge and awareness of the instrument is vital. As proper diagnosis is the key for a better prognosis in any treatment. This study assessed the knowledge attitude and practice of dental mirrors on endodontic procedures and found out that $49 \%$ of the participants were aware of the parts of a dental mirror, which is quite satisfactory, 36\% of the participants preferred disposable mouth mirrors for diagnostic purposes as it is easy to manage does not need sterilization procedure provided it is properly disposed. $65 \%$ of the participants agreed to invest in a good quality mouth mirror after completing the survey.

\section{ACKNOWLEDGMENTS}

The authors would like to acknowledge the participants of the study.

Conflict of Interest: The authors declare no conflict of interest.

\section{REFERENCES}

Anwar, A. I. (2018) 'Correlation between mental health and caries status In Primary School Students', Journal of Dentomaxillofacial Science, p. 112. doi: 10.15562/ jdmfs.v3i2.639.

Azeem, R. A. and Sureshbabu, N. M. (2018) 'Clinical performance of direct versus indirect composite restorations in posterior teeth: A systematic review', Journal of conservative dentistry: JCD, 21(1), pp. 2-9. Chalmers, J. M. et al. (2005) 'The Oral Health Assessment Tool - Validity and reliability', Australian Dental Journal, pp. 191-199. doi: 10.1111/j.1834-7819.2005. tb00360.x.

Díaz, M. J. et al. (2001) 'Assessment of a preclinical training system with indirect vision for dental education', European journal of dental education: official journal of the Association for Dental Education in Europe. Wiley Online Library, 5(3), pp. 120-126.

Dimashkieh, M. R. (2002) 'A reverse-angle dental mirror', The Journal of prosthetic dentistry. Elsevier, 87(3), pp. 345-346.

Ganavadiya, R. et al. (2014) 'Disinfecting efficacy of three chemical disinfectants on contaminated diagnostic instruments: A randomized trial', Journal of Basic and Clinical Pharmacy, p. 98. doi: 10.4103/09760105.141946.

Govindaraju, L., Neelakantan, P. and Gutmann, J. L. (2017) 'Effect of root canal irrigating solutions on the compressive strength of tricalcium silicate cements', Clinical oral investigations, 21(2), pp. 567-571.

Janani, K. and Sandhya, R. (2019) 'A survey on skills for cone beam computed tomography interpretation among endodontists for endodontic treatment procedure', Indian journal of dental research: official publication of Indian Society for Dental Research, 30(6), pp. 834-838.

Jenarthanan, S. and Subbarao, C. (2018) 'Comparative evaluation of the efficacy of diclofenac sodium administered using different delivery routes in the management of endodontic pain: A randomized controlled clinical trial', Journal of conservative dentistry: JCD, 21(3), pp. 297-301.

Khandelwal, A. and Palanivelu, A. (2019) 'Correlation Between Dental Caries And Salivary Albumin In Adult Population In Chennai: An In Vivo Study', Brazilian Dental Science, 22(2), pp. 228-233.

Kim, S. and Baek, S. (2004) 'The microscope and endodontics', Dental Clinics of North America, pp. 11-18. doi: 10.1016/j.cden.2003.12.001.

Knight, G. W. and Guenzel, P. J. (1994) 'Design and validation of mirror skills instruction', Journal of Dental Education, pp. 752-761. doi: 10.1002/j.00220337.1994.58.10.tb02896.x.

Kunovich, R. S., Rosenblum, R. H. and Beck, F. M. (1987) 'The effect of training on indirect vision skills', Journal of Dental Education, pp. 716-719. doi: 10.1002/j.00220337.1987.51.12.tb02167.x.

Malli Sureshbabu, N. et al. (2019) 'Concentrated Growth Factors as an Ingenious Biomaterial in Regeneration of Bony Defects after Periapical Surgery: A Report of Two Cases', Case reports in dentistry, 2019, p. 7046203.

Manohar, M. P. and Sharma, S. (2018) 'A survey of the knowledge, attitude, and awareness about the principal choice of intracanal medicaments among the general dental practitioners and nonendodontic specialists', Indian journal of dental research: official publication of Indian Society for Dental Research, 29(6), pp. 716-720.

Mital, P. et al. (2014) 'RECENT ADVANCES IN DETECTION AND DIAGNOSIS OF DENTAL CARIES', Journal of Evolution of Medical and Dental sciences, pp. 177-191. doi: 10.14260/jemds/1807.

Nandakumar, M. and Nasim, I. (2018) 'Comparative evaluation of grape seed and cranberry extracts in preventing enamel erosion: An optical emission spectrometric analysis', Journal of conservative dentistry: JCD, 21(5), pp. 516-520.

Neumann, L. M. (1988) 'A simple exercise for teaching mirror vision skills', Journal of Dental Education, pp. 170172. doi: 10.1002/j.0022-0337.1988.52.3.tb02186.x.

Ozdemir, D. (2014) 'Dental caries and preventive strategies', Journal of Educational and Instructional Studies in the World. researchgate.net, 4(4), pp. 2024.

Poorni, S., Srinivasan, M. R. and Nivedhitha, M. S. (2019) 'Probiotic strains in caries prevention: A systematic review', Journal of conservative dentistry: JCD, 22(2), pp. 123-128.

Rajakeerthi, R. and Ms, N. (2019) 'Natural Product as the Storage medium for an avulsed tooth - A Systematic Review', Cumhuriyet Dental Journal, 22(2), pp. 249256.

Rajendran, R. et al. (2019) 'Comparative Evaluation of Remineralizing Potential of a Paste Containing Bioactive Glass and a Topical Cream Containing Casein 
Phosphopeptide-Amorphous Calcium Phosphate: An in Vitro Study', Pesquisa brasileira em odontopediatria e clinica integrada, 19(1), pp. 1-10.

Ramarao, S. and Sathyanarayanan, U. (2019) 'CRA Grid - A preliminary development and calibration of a paper-based objectivization of caries risk assessment in undergraduate dental education', Journal of conservative dentistry: JCD, 22(2), pp. 185-190.

Rieuwpassa, I. E. et al. (2016) 'Three in one dental mirror: inovation of oral diagnostic instrument', Journal of Dentomaxillofacial Science4. jdmfs.org, 2, pp. 75-78. Rubinstein, R. (1997) 'The anatomy of the surgical operating microscope and operating positions', Dental clinics of North America. europepmc.org, 41(3), pp. 391-413.

Rubinstein, R. (2005) 'Magnification and illumination in apical surgery', Endodontic Topics, pp. 56-77. doi: 10.1111/j.1601-1546.2005.00159.x.

Selwitz, R. H., Ismail, A. I. and Pitts, N. B. (2007) 'Dental caries', The Lancet. Elsevier, 369(9555), pp. 51-59.

Siddique, R. et al. (2019) 'Qualitative and quantitative analysis of precipitate formation following interaction of chlorhexidine with sodium hypochlorite, neem, and tulsi', Journal of conservative dentistry: JCD, 22(1), pp. 40-47.
Siddique, R. and Nivedhitha, M. S. (2019) 'Effectiveness of rotary and reciprocating systems on microbial reduction: A systematic review', Journal of conservative dentistry: JCD, 22(2), pp. 114-122.

Siddique, R., Nivedhitha, M. S. and Jacob, B. (2019) 'Quantitative analysis for detection of toxic elements in various irrigants, their combination (precipitate), and para-chloroaniline: An inductively coupled plasma mass spectrometry study', Journal of conservative dentistry: JCD, 22(4), pp. 344-350.

Surathu, N. and Nasim, I. (2015) 'Assesment of the use of a dental mirror', JDMS, 14, p. 115.

Teja, K. V., Ramesh, S. and Priya, V. (2018) 'Regulation of matrix metalloproteinase-3 gene expression in inflammation: A molecular study', Journal of conservative dentistry: JCD, 21(6), pp. 592-596.

Willis, D. O. and Kincheloe, J. E. (1983) 'Teaching dental students mirror vision skills', Journal of Dental Education, pp. 311-316. doi: 10.1002/j.00220337.1983.47.5.tb01680.x.

Willis, D. O., Scheetz, J. P. and Kincheloe, J. E. (1987) 'A comparison of two- and three-dimensional exercises in the acquisition of mirror vision skills', Journal of Dental Education, pp. 190-191. doi: 10.1002/j.00220337.1987.51.4.tb02096.x. 